\title{
DISCHARGE PLANNING MENTORING PROGRAM TO PREVENT REHOSPITALIZATION FOR PATIENTS WITH CONGESTIVE HEART FAILURE
}

\author{
Jennifa, Tri Nur Kristina, M. Rofi'i \\ Universitas Diponegoro, Semarang, Central Java, Indonesia
}

\begin{abstract}
Background: Every year, thousands of congestive heart failure (CHF) patients are readmitted to the hospital within 30 days of discharge. Hospital readmissions are costly, extensive, and in some cases avoidable. One of the factors known to increase a patient's risk for readmission is the lack of patient engagement and self-efficacy regarding the treatment plan. The purpose of this study was to determine discharge planning mentoring program to prevent re-hospitalization for patient with CHF.

Subjects and Method: This was a quasi-experiment with posttest only design conducted at PKU Muhammadiyah, Gamping, Yogyakarta. A sample of 28 patients with CHF was selected for this study. The dependent variable was readmission 30 days after discharge. The independent variable was discharge planning mentoring. The data were analyzed by chisquare.

Results: $78.6 \%$ CHF patients who received mentoring discharge planning were not readmitted.

Conclusion: Mentoring discharge planning program is effective to decrease re-hospitalization of CHF patients.
\end{abstract}

Keywords: congestive heart failure, discharge planning, re-hospitalization

\section{Correspondence:}

Jennifa. Universitas Diponegoro, Semarang, Central Java, Indonesia.

Email: jejennio9@gmail.com. Mobile: 082136125405. 